\title{
Pengaruh umpan buatan warna merah dan kuning terhadap hasil tangkapan pancing pompa di perairan pantai Desa Bajo, Kabupaten Minahasa Selatan
}

\author{
The effect of red and yellow artificial bait colors to the pump handline catches in \\ Bajo Village waters, South Minahasa \\ HERMANUS B. USILI*, IVOR L. LABARO dan MARIANA E. KAYAdOE \\ Program Studi Pemanfaatan Sumberdaya Perikanan, Fakultas Perikanan dan Ilmu Kelautan, \\ Universitas Sam Ratulangi, Manado 95115
}

\begin{abstract}
Pump handline is a traditional fishing gear commonly used by fishermen in the Gulf Amurang to catch demersal fishes/reef fishes. This handline uses artificial baits made of fiber cloth of different colors, and an effective bait color is unknown yet. This research aims to study the effect of artificial bait colors on the pump handline catches, and to identify the species. This research was conducted through experimental methods by operating four pump handline units using red and yellow artificial baits starting at 07:00 am until 14:00 pm. The catches were 33 fishes, consisting of 23 fishes caught with red baits and 10 fishes caught with yellow baits. The results showed that red and yellow artificial baits on the pump handline had different number of catches, the average catches per hour of the respective bait colors were 3.83 (4 fishes) and 1.67 ( 2 fishes). The catch species consisted of 17 species, and was predominated by groupers, parrot fish, snappers and goat fish.
\end{abstract}

Keywords: pump handline, artificial bait, demersal fish/reef fishes.

\begin{abstract}
ABSTRAK
Pancing pompa merupakan alat tangkap ikan tradisional yang umum dioperasikan oleh nelayan di Teluk Amurang untuk menangkap jenis-jenis ikan demersal/ikan-ikan karang. Umpan yang digunakan adalah umpan buatan dari serat kain yang warnanya bervariasi, dan warna umpan yang efektif belum diketahui. Sehingga tujuan penelitian ialah mempelajari pengaruh warna umpan buatan terhadap hasil tangkapan pancing pompa dan mengidentifikasi jenis-jenis ikan yang tertangkap. Penelitian ini dilakukan melalui metode eksperimental dengan mengoperasikan empat unit pancing pompa yang menggunakan umpan buatan warna merah dan kuning pada pukul 07.00 hingga pukul 14:00 Wita. Hasil tangkapan yang diperoleh berjumlah 33 ekor ikan, terdiri dari 23 ekor tertangkap dengan umpan buatan warna merah dan 10 ekor tertangkap dengan umpan buatan warna kuning. Hasil analisis menyimpulkan bahwa umpan buatan warna merah dan warna kuning pada pancing pompa ternyata berbeda, karena umpan warna merah mendapatkan hasil rata-rata 3,83 (4 ekor) per jam, sedangkan umpan warna kuning rata-rata 1,67 ( 2 ekor) per jam. Jenis-jenis ikan yang tertangkap dengan pancing pompa terdiri dari 17 spesies, dan didominasi oleh goropa, kakatua, gorara dan biji nangka.
\end{abstract}

Kata-kata kunci: pancingpompa, umpan buatan, ikandemersal/ikankarang

\section{PENDAHULUAN}

Pancing adalah salah satu alat tangkap yang umum dikenal oleh masyarakat nelayan. Adapun bagian-

\footnotetext{
${ }^{*}$ Penulis untuk penyuratan; email: hermanus2404@yahoo.com
}

bagian pokok dari pancing adalah mata pancing, umpan dan tali pancing (Gunarso, 1996).

Pancing pompa termasuk salah satu jenis pancing ulur (hand line) yang ditujukan untuk menangkap ikan-ikan demersal dan ikan karang. Pengoperasian pancing pompa oleh nelayan di Kabupaten Minahasa Selatan dilakukan pada daerah terumbu karang (coral reef) di perairan 
Teluk Amurang. Pengoperasian alat ini relatif sederhana, tidak banyak menggunakan peralatan bantu seperti halnya alat tangkap yang lain.

Hingga sekarang para nelayan pancing pompa ini menggunakan umpan buatan yang warnanya bervariasi. Sehingga warna umpan yang efektif digunakan pada pancing pompa untuk menangkap ikan-ikan demersal/ikan-ikan karang belum diketahui. Berdasarkan rumusan masalah ini maka perlu diadakan suatu penelitian tentang warna umpan yang baik untuk digunakan dalam pengoperasian pancing pompa. Penelitian ini bertujuan untuk mempelajari pengaruh warna umpan buatan terhadap hasil tangkapan ikan dan mengidentifikasi jenis-jenis ikan yang tertangkap dengan pancing pompa.

\section{METODE PENELITIAN}

Penelitian ini dilakukan di perairan pantai Desa Bajo Teluk Amurang Kabupaten Minahasa Selatan, dengan mengikuti metode eksperimental yaitu suatu rancangan percobaan yang diujicobakan untuk memperoleh informasi tentang persoal- an yang sedang diteliti (Sudjana, 1994). Sedangkan dasar penelitian ini adalah studi kasus yaitu penelitian yang mempelajari kasus tertentu pada obyek yang terbatas (Nasir, 1985). Kasus yang akan diteliti adalah penggunaan perbedaan warna umpan pada pancing pompa untuk menangkap ikan demersal di perairan pantai Desa Bajo.

Teknik pengumpulan data untuk mendekati tujuan yang telah ditetapkan, yaitu mempelajari pengaruh warna umpan buatan terhadap hasil tangkapan, dilakukan dengan mengoperasikan empat unit alat tangkap pancing pompa. Dua jenis warna umpan buatan yang digunakan sebagai perlakuan yaitu warna kuning dan merah. Kedua jenis perlakuan tersebut ditempatkan secara acak pada empat unit perahu pemancing. Setelah sampai di daerah penangkapan operasi penangkapan dilakukan dengan cara menurunkan pancing pompa secara bersama-sama oleh ke empat perahu penangkap. Selanjutnya ikan hasil tangkapan dicatat berdasarkan warna umpan yang menjadi perlakuan setiap jam. Pengumpulan data ini berlangsung selama 6 jam, sejak pukul 07.00 hingga pukul 14.00 Wita.

Tabel 1. Spesifikasi alat tangkap pancing pompa

\begin{tabular}{llcccc}
\hline \multicolumn{1}{c}{ Bagian Alat } & \multicolumn{1}{c}{ Material } & Nomor & Berat (gr) & Panjang (m) & Jumlah (buah) \\
\hline Penggulung & Plastik/Kayu & - & - & - & 1 \\
Tali Utama & PA mono & 500 & - & $100-200$ & 1 \\
Tali Pengantar & PA mono & 200 & - & $4-5$ & 1 \\
Swivel & Fe & 04 & - & - & 1 \\
Mata Pancing & Fe & 13 & - & - & 4 \\
Umpan & Benang Sutera Warna & - & - & - & 1 \\
& Merah dan Kuning & - & & & 1 \\
Pemberat & Batu & - & $200-250$ & - & 1 \\
\hline
\end{tabular}

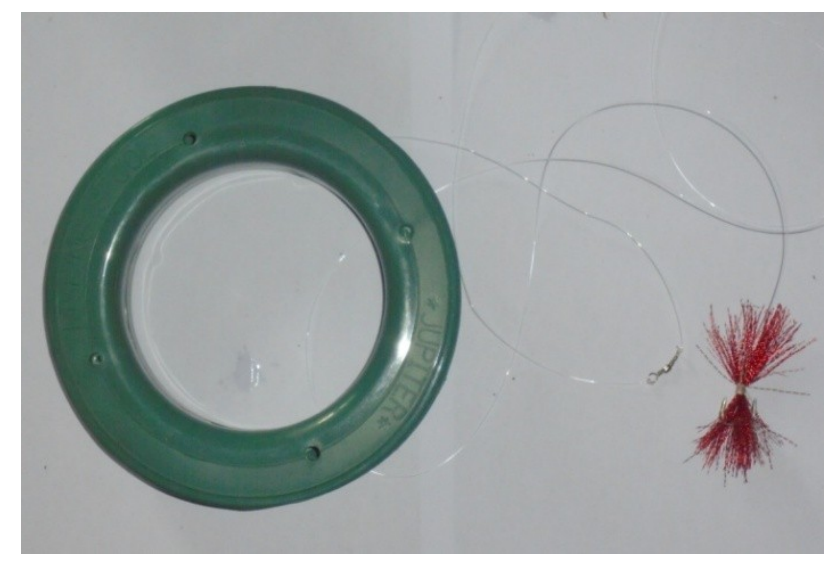

Gambar 1. Alat tangkap pancing pompa 

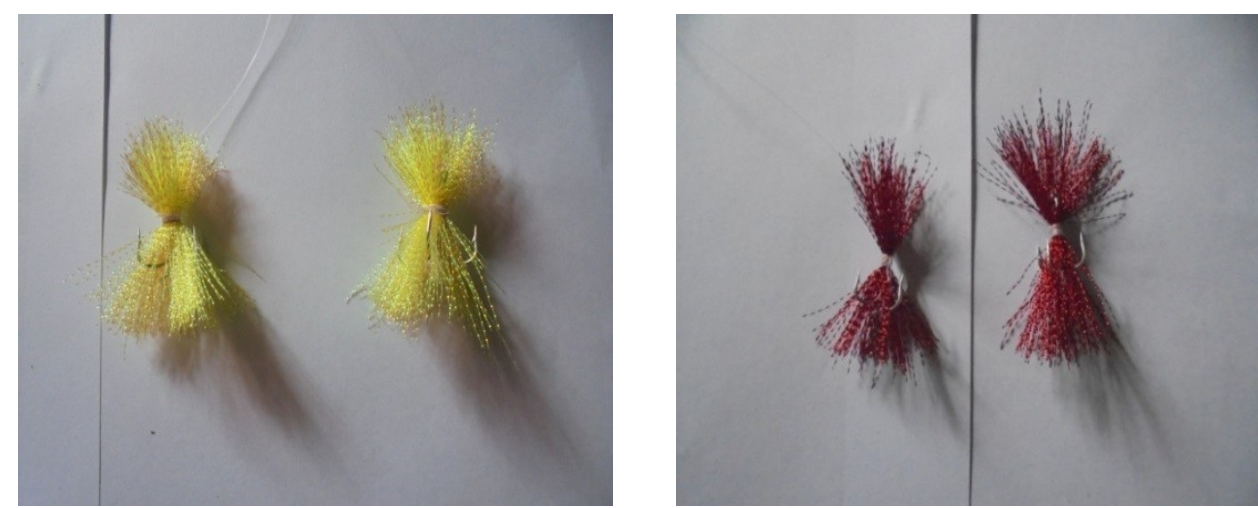

Gambar 2.Umpan buatan warna kuning dan merah

Untuk memenuhi persyaratan analisis dalam menarik kesimpulan, maka dirumuskan hipotesis sebagai berikut:

$\mathrm{H}_{0}=$ Umpan buatan warna merah dan warna kuning pada pancing pompa sama,

$\mathrm{H}_{1}=$ Umpan buatan warna merah dan warna kuning pada pancing pompa berbeda,

di mana, $\mathrm{H}_{0}$ diterima $\left(\mathrm{H}_{1}\right.$ ditolak) apabila $\mathrm{t}_{\text {hitung }}<$ $\mathrm{t}_{\text {tabel}}$, atau $\mathrm{H}_{0}$ ditolak $\left(\mathrm{H}_{1}\right.$ diterima $)$ apabila $\mathrm{t}_{\text {hitung }} \geq$ $t_{\text {tabel }}$. Selanjutnya $t$ dihitung dengan mengunakan analisis komparatif dua sampel berkorelasi (Hasan, 2004), dengan rumus sebagai berikut:

di mana

$$
T=\frac{\bar{X}-\bar{Y}}{\sqrt{\frac{\sum D^{2}-\frac{\left(\sum D\right)^{2}}{n}}{n(n-1)}}}
$$

$$
\begin{aligned}
& \mathrm{T}=\mathrm{t} \text { hitung } \\
& \bar{X}=\mathrm{X} \text { rata-rata (umpan merah) } \\
& \bar{Y}=\mathrm{Y} \text { rata-rata (umpan kuning) }
\end{aligned}
$$

$$
\begin{aligned}
& \mathrm{D}=\mathrm{X} \text { rata-rata }-\mathrm{Y} \text { rata-rata } \\
& \mathrm{n}=\text { Jumlah jam operasi penangkapan. }
\end{aligned}
$$

\section{HASIL DAN PEMBAHASAN}

Hasil tangkapan pancing pompa selama 2 hari penelitian berjumlah 33 ekor, yang terdiri dari 23 ekor tertangkap dengan umpan buatan warna merah, dan 10 ekor tertangkap dengan umpan buatanwarnakuning. Jumlah hasil tangkapan pancing pompa selama 6 jam operasi penangkapan dengan 2 perlakuan dipaparkan secara rinci pada Tabel 2.

Berdasarkan perhitungan rata-rata hasil tangkapan setiap jam operasi maka umpan warna merah mendapatkan hasil 3-5 ekor atau rata-rata 3,83 (4 ekor) per jam, sedangkan umpan warna kuning mendapatkan hasil lebih sedikit yaitu 1-2

\begin{tabular}{|c|c|c|c|c|}
\hline \multirow[t]{2}{*}{ No } & \multirow{2}{*}{$\begin{array}{c}\text { Jam Operasi } \\
\text { Penangkapan }\end{array}$} & \multicolumn{2}{|c|}{ Warna Umpan } & \multirow[t]{2}{*}{ Total } \\
\hline & & Merah & Kuning & \\
\hline 1 & $07.00-08.00$ & 4 & 2 & 6 \\
\hline 2 & $08.00-09.00$ & 5 & 2 & 7 \\
\hline 3 & $09.00-10.00$ & 4 & 2 & 6 \\
\hline 4 & $10.00-11.00$ & 3 & 2 & 5 \\
\hline 5 & $11: 00-12.00$ & 3 & 1 & 4 \\
\hline 6 & $13.00-14.00$ & 4 & 1 & 5 \\
\hline Total & & 23 & 10 & 33 \\
\hline Rataan & & 3,83 & 1,67 & 5,50 \\
\hline
\end{tabular}
ekor atau rata-rata 1,67 (2 ekor) per jam. Hasil tangkapan yang diperoleh pancing pompa umpan warna merah dan umpan warna kuning setiap jam operasi, lebih jelas digambarkan pada Gbr. 3 .

Tabel 2. Jumlah hasil tangkapanpancing pompa selama penelitian 


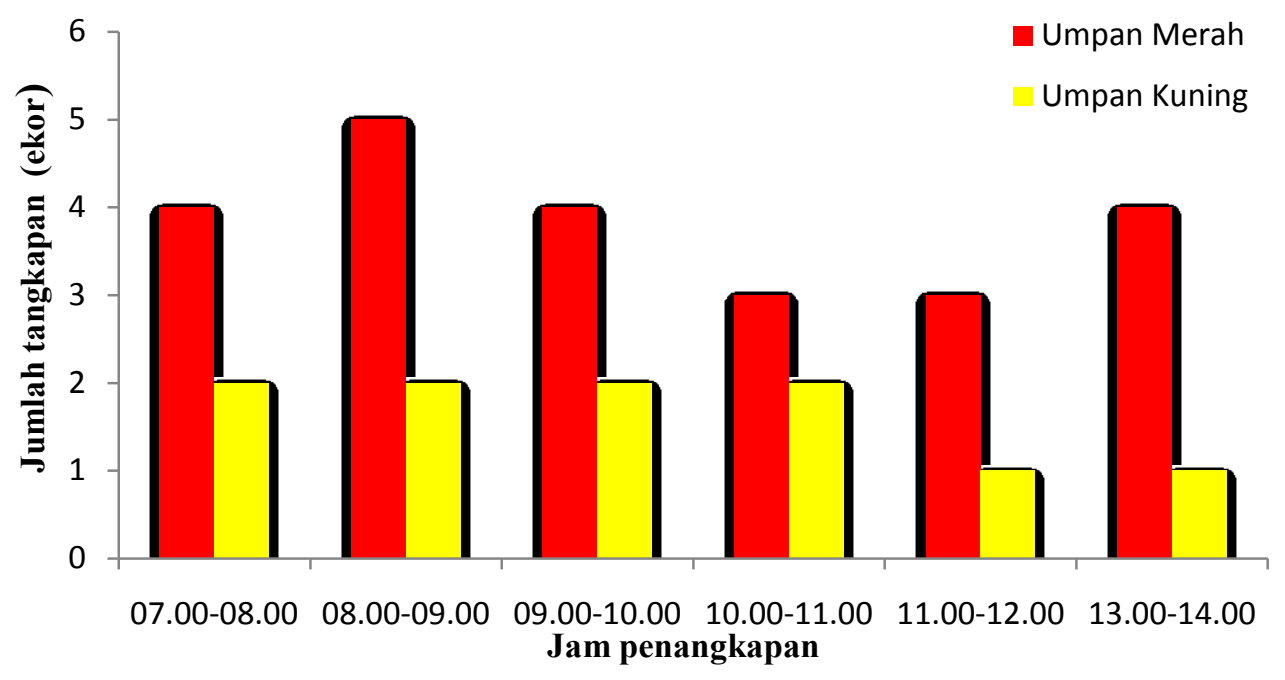

Gambar 3. Grafik jumlah hasil tangkapan setiap waktu operasi.

Tabel 3. Jumlah dan jenis ikan yang tertangkap berdasarkan perlakuan

\begin{tabular}{lllccc}
\hline No & Nama genus dan spesies * & Nama lokal & Merah & Kuning & Total \\
\hline 1 & Caranx sexfasciatus & Bobara & 2 & 1 & 3 \\
2 & Caranx tille & Bobara & 1 & - & 1 \\
3 & Cephalopholis micoprion & Goropa hitam & 1 & - & 1 \\
4 & Oxycheilinus digramma & Kakatua & 1 & - & 1 \\
5 & Scarus quoyi & Kakatua biru & 1 & 1 & 2 \\
6 & Scarus flavipectoralis & Maming & 1 & 2 & 3 \\
7 & Variola albimarginata & Goropa gunting & 2 & 1 & 3 \\
8 & Plectropomus leopardus & Goropa sunuh & 3 & 1 & 4 \\
9 & Priachantus sagittarius & Bulan-bulan & 1 & - & 1 \\
10 & Lutjanus lutjanus & Gorara & 2 & - & 2 \\
11 & Lutjanus rufolineatus & Gorara & 2 & 1 & 3 \\
12 & Lethrinus harak & Lencam & 1 & - & 1 \\
13 & Parupeneus multifasciatus & Biji nangka & 2 & 1 & 3 \\
14 & Parupeneus heptacanthus & Biji nangka & 1 & - & 1 \\
15 & Aphareus rutilans & Kurisi perak & 1 & - & 1 \\
16 & Terapon jarbua & Kerong-kerong & 1 & 1 & 2 \\
17 & Loligo sp & Cumi-cumi & - & 1 & 1 \\
\hline Jumlah & & 23 & 10 & 33 \\
\hline
\end{tabular}

Pada Tabel 3 dijelaskan bahwa hasil tangkapan yang diperoleh pancing pompa selama penelitian umumnya adalah ikan-ikan karang, dan didominasi oleh 3 jenis ikan goropa yaitu goropa sunuh 4 ekor, goropa gunting 3 ekor dan goropa hitam 1 ekor. Kemudian diikuti oleh ikan jenis kakatua dan maming yang termasuk genus Scarus, gorara serta biji nangka.

Data hasil tangkapan selama 2 hari pengamatan dikelompokkan menurut waktu pengamatan dan dianalisis menurut perlakuan warna umpan yang berbeda yaitu merah dan kuning. Hasil analisis uji $\mathrm{t}$ dijelaskan pada Tabel 4. Hasil analisis menunjukkan bahwa $\mathrm{t}$ hitung $=2,878>\mathrm{t}$ tabel ${ }_{0,05 ; 5}=2,571$; sehingga menolak $\mathrm{H}_{0}$ dan menerima $\mathrm{H}_{1}$. Hal ini menjelasan bahwa umpan buatan warna merah dan warna kuning pada pancing pompa ternyata berbeda. 
H.B. Usili dkk.

Tabel 4. Analisis uji t terhadap hasil tangkapan pancing pompa

\begin{tabular}{ccccc}
\hline Waktu Operasi & \multicolumn{2}{c}{ Warna Umpan Buatan } & \multirow{2}{*}{ D $(\mathrm{X}-\mathrm{Y})$} & \multirow{2}{*}{$\mathrm{D}^{2}$} \\
\cline { 2 - 3 } Penangkapan & Merah $(\mathrm{X})$ & Kuning $(\mathrm{Y})$ & & 4 \\
$07.00-08.00$ & 4 & 2 & 3 & 9 \\
$08.00-09.00$ & 5 & 2 & 2 & 4 \\
$09.00-10.00$ & 4 & 2 & 1 & 1 \\
$10.00-11.00$ & 3 & 2 & 2 & 4 \\
$11: 00-12.00$ & 3 & 1 & 3 & 9 \\
$13.00-14.00$ & 4 & 1 & 13 & 31 \\
\hline Jumlah & 23 & 10 & & \\
Rataan & 3,83 & 1,67 & & \\
\hline
\end{tabular}

Warna merah lebih terlihat (jarak) di air dibandingkan dengan warna kuning sehingga kemungkinan ikan tujuan penangkapan bukan karena tertarik karena umpan tetapi lebih pada jarak pandang maupun sifat memakan yang lebih mengkilat.

Hasil tangkapan umumnya adalah ikan-ikan karang, karena daerah penangkapannya berada di sekitar terumbu karang (napo), dan tertangkapnya ikan- ikan yang penyebarannya di perairan pantai seperti kerong-kerong, disebabkan karena jarak daerah penangkapan dari pantai hanya berkisar antara 500-1000 m, dengan kedalaman 20-30 m.

\section{KESIMPULAN}

1) Umpan buatan warna merah dan warna kuning pada pancing pompa ternyata berbeda, karena umpan warna merah mendapatkan hasil rata-rata 3,83 (4 ekor) per jam, sedangkan umpan warna kuning mendapatkan hasil rata-rata 1,67 (2 ekor) per jam.

2) Jenis-jenis ikan yang tertangkap dengan pancing pompa terdiri dari 17 spesies, dan didominasi oleh goropa, kakatua, gorara dan biji nangka.

\section{DAFTAR PUSTAKA}

Gunarso, W. 1996. Tingkah laku ikan dan perikanan pancing. Fakultas Perikanan Institut Pertanian Bogor, Bogor.

Hasan, I. 2004. Analisis Data Penelitian dengan Statistik. PT. Bumi Aksara, Jakarta.

Sudjana, 1994. Desain dan Analisis Eksperimen. Edisi III. Tarsito, Bandung.

White, W.T., P.R. Last Dharmadi, B Faizah U., B.I. Chodrijah, Prisantoso, J.J. Pogonoski, M. Puckridge, and S.J.M Blaber. 2013. Market Fishes of Indonesia (Jenisjenis Ikan di Indonesia). ACIAR Monograph No. 155. Australian Centre for International Agricultural Research: Canberra.

Nasir, M. 1985. Metode Penelitian. Ghalia Indonesia, Jakarta. 